\title{
Serum uric acid concentration is associated with hypertensive retinopathy in hypertensive chinese adults
}

\author{
Xuling Chen ${ }^{1}$, Ying Meng ${ }^{1}$, Jun Li ${ }^{1}$, Hiacheng She ${ }^{2}$, Liang Zhao ${ }^{1}$, Jing Zhang ${ }^{1}$, Yuan Peng ${ }^{1}$, Kun Shang ${ }^{1}$, \\ Yadi Zhang ${ }^{1}$, Xiaopeng Gu', Wenbin Yang ${ }^{3}$, Yan Zhang ${ }^{4}$, Jianping $\mathrm{Li}^{4}$, Xianhui Qin ${ }^{5}$, Binyan Wang ${ }^{5}$, Xiping Xu ${ }^{5}$, \\ Fanfan Hou ${ }^{5}$, Genfu Tang ${ }^{6}$, Rongfeng Liao ${ }^{3,7}$, Yong Huo $^{4^{*}}$ and Liu Yang ${ }^{1 *}$
}

\begin{abstract}
Background: This cross sectional investigation included 12,966 subjects with hypertension, a cohort of the China Stroke Primary Prevention Trial (CSPPT), a randomized, multicenter clinical trial. This study aimed to explore the correlation between serum uric acid (SUA) concentration and hypertensive retinopathy in hypertensive adults.

Methods: Diagnosis of hypertensive retinopathy was determined by non-mydriatic fundus photography and classified with Keith-Wagener-Barker (KWB) system. The correlation of SUA levels with hypertensive retinopathy prevalence and severity was assessed by statistical analysis.

Results: 9848 (75.95\%) subjects were diagnosed with hypertensive retinopathy with the following retinopathy grade distribution: grade 1: 58.80\%, grade 2: 14.81\%, and grade 3-4: 2.34\%. SUA levels were significantly associated with hypertensive retinopathy prevalence. Patients with hypertensive retinopathy had higher SUA levels than those without hypertensive retinopathy. Patients in the highest uric acid quartile had an odds ratio for hypertensive retinopathy of 1.21 compared to patients in the lowest uric acid quartile (OR=1.21, 95\% Cl: 1.05-1.40, $P=0.008$ ). When compared to the non-hyperuricemia group, those in the hyperuricemia group had an odds ratio for hypertensive retinopathy of $1.18(\mathrm{OR}=1.18,95 \% \mathrm{Cl}: 1.05-1.33, P=0.004)$. Every $1 \mathrm{mg} / \mathrm{dl}$ increase in uric acid concentration was significantly associated with a $6 \%$ higher odds of hypertensive retinopathy $(O R=1.06,95 \%$ Cl: $1.02-1.10, P=0.002)$.
\end{abstract}

Conclusions: The prevalence of hypertensive retinopathy was high (75.95\%) among hypertensives in our patients cohort. In addition, SUA concentration was significantly associated with hypertensive retinopathy.

Keywords: Serum Uric Acid Concentration, Hypertensive Retinopathy, Hypertension, Hyperuricemia, Keith-WagenerBarker system

\section{Background}

Hypertension affects more than 330 million people in China, it is the most common chronic disease in the Chinese population [1]. Hypertensive retinopathy (HR) is one of the micro vascular complications of hypertension with an insidious onset, which, if left untreated, can

\footnotetext{
* Correspondence: huoyong@263.net.cn; lucy02114@163.com

${ }^{4}$ Department of Cardiology, Peking University First Hospital, No.8 Xishiku Street, Xicheng District, Beijing 100034, China

${ }^{1}$ Department of Ophthalmology, Key Laboratory of Vision Loss and Restoration, Ministry of Education, Peking University First Hospital, No.8 Xishiku Street, Xicheng District, Beijing 100034, China

Full list of author information is available at the end of the article
}

possibly open the way for retinal vascular obstruction (RVO), retinal thrombus, ischemic optic neuropathy (ION) and vitreous hemorrhage [2, 3]. Furthermore, the retinal vascular bed, the only vascular bed that can be observed by non-invasive procedures in vivo, is regarded as an essential indicator to evaluate the status of systemic microvasculature [4]. Many studies have proved the value of the retinal vascular in predicting the severity of target organ damage, including cardiovascular, renal and cerebrovascular disease $[5,6]$. The prevalence of $\mathrm{HR}$ in hypertensive patients varied among different researches $(30.6 \%-94.6 \%)$ [7-9]. To date there 
has been no large sample, epidemiologic statistical reports on HR in China.

Some studies have explored the risk factors for HR, including endothelial dysfunction [10], oxidative stress [11], and low-grade systemic inflammation [12]. However, other risk factors, such as serum triglyceride levels, serum uric acid (SUA) and metabolic syndrome, have been studied with relatively inconclusive results. Uric acid is the final product of purine metabolism in humans. Hyperuricemia is a predisposing condition for gout and is linked with metabolic syndrome [13], resulting from increased production of uric acid coupled with excretion dysfunction. It was also regarded as an independent risk factor for hypertension. Two meta-analysis of published prospective studies showed that the overall risk for incident hypertension increased by $13 \%$ and $15 \%$ per $1 \mathrm{mg} / \mathrm{dl}$ increase in SUA level respectively [14, 15]. Numerous studies have suggested that SUA is correlated with some ocular diseases [16], especially diabetic retinopathy [17]. Our study sought to characterize epidemiological features of $\mathrm{HR}$ and investigate the association between SUA and HR. We were interested whether SUA is an independent risk factor contributing to HR.

\section{Methods}

\section{Study design and participants}

All subjects in this study came from the China Stroke Primary Prevention Trial (CSPPT), conducted from May 19, 2008, to August 24, 2013, in 32 communities in the Jiangsu and Anhui provinces of China [18]. The study complied with the Helsinki Declaration and was approved by the Ethics Committee of the Institute of Biomedicine, Anhui Medical University, Hefei, China (FWA assurance number FWA00001263). All participants provided written informed consent. CSPPT study was a large communitybased, randomized, multicenter, double blind, and actively controlled trial designed to evaluate whether combination therapy with enalapril maleate and folic acid tablets combined were more effective in preventing stroke in Chinese adults with hypertension than enalapril maleate alone. Details of the trial have been described elsewhere (http:// clinicaltrials.gov/ct2/show/NCT00794885).

Our study included a total of 20,702 hypertensive subjects, 13,140 had fundus picture, among them, and 155 subjects were excluded for difficult gradable fundus photographs, for the reason of serious opacity of refractive media or terrible fixation vision. After excluding 7736 subjects who were missing either gradable fundus photographs or analysis of SUA, a total of 12,966 subjects were analyzed.

\section{Classification of Hypertensive Retinopathy}

Non-mydriatic fundus photographs were taken in the posterior pole and macula-centered, using fundus cameras
(Topcon TRC-NW8 Non-Mydriatic Retinal Camera, Canon CR-2 AF Non-Mydriatic Retinal Camera and Kowa nonmyd 7 Fundus Camera). All the photographs were randomly evaluated by four professional ophthalmologists with double mask, and we ensured the results of science and reliability through good consistency checks (kappa between 0.71-0.95). HR was classified into grades 1-4 according to the Keith-Wagener-Barker (KWB) system (for details of classification see [19] Table 1).

\section{Laboratory Examinations}

Laboratory examinations were performed at the core lab of the National Clinical Research Center for Kidney Disease (Nanfang Hospital, Guangzhou, China). Fasting serum uric acid (SUA), lipids (serum total cholesterol, high density lipoprotein - HDL-C, and triglycerides), serum creatinine, blood glucose and homocysteine were measured by using automatic clinical analyzers (Beckman Coulter), serum folic acid were measured by using a chemiluminescent immunoassay (New Industrial). Diabetes mellitus (DM) was defined as a fasting plasma glucose concentration greater than or equal to $7.0 \mathrm{mmol} / \mathrm{l}$, or a history of diabetes paired with the use of an oral antidiabetic drug. Hyperuricemia was defined as serum uric acid exceeding $7.0 \mathrm{mg} / \mathrm{dl}$ in males and $6.0 \mathrm{mg} / \mathrm{dl}$ in females.

\section{Demographic data}

All participants were interviewed using a standardized questionnaire including age, gender, sociodemographic status, education, occupation, diet, lifestyle, health behavior, medical history and personal history including smoking status, alcohol consumption, and known systemic disease. Current smoking was defined as smoking one cigarette per day for at least half a year. Current drinking was defined as drinking once per week for at least half a year. Anthropometric measurements were taken according to a standard operating procedure. Body Mass Index (BMI) was calculated as weight (kilograms) divided by height (meters) squared.

\begin{tabular}{ll}
$\begin{array}{l}\text { Table } 1 \text { The Keith-Wagener-Barker classification system for } \\
\text { hypertensive retinopathy }\end{array}$ \\
\hline Grade & Features \\
\hline None & $\begin{array}{l}\text { No detectable positive signs } \\
\text { Mild or moderate generalized retinal arteriolar } \\
\text { narrowing, arteriovenous tortuosity }\end{array}$ \\
2 & $\begin{array}{l}\text { Definite focal narrowing and arteriovenous nipping, } \\
\text { crossing compression }\end{array}$ \\
3 & $\begin{array}{l}\text { Copper wire or silver wire artery, signs of grade 2 } \\
\text { retinopathy plus retinal hemorrhages, exudates and } \\
\text { cotton wool spots } \\
\text { Severe grade } 3 \text { retinopathy plus papilledema or } \\
\text { retinal edema }\end{array}$ \\
\hline
\end{tabular}




\section{Blood Pressure (BP) measurements}

Systolic and diastolic BP (SBP/DBP $\mathrm{mmHg}$ ) was measured after subjects resting for $30 \mathrm{~min}$; participants were seated with their right arms supported at the level of the heart for BP measurements. BP was measured using a mercury sphygmomanometer with an appropriate cuff size, and recorded as the mean of three measurements, with one-minute intervals between each. Hypertension was defined as a BP greater than or equal to $140 \mathrm{mmHg}$ systolic and/or $90 \mathrm{mmHg}$ diastolic.

\section{Statistical analysis}

All analyses were performed using Empower Stats statistical software (http://www.empowerstats.com, X\&Y Solutions, Inc. Boston, MA) and the statistical package $\mathrm{R}$ (http://www.r-project.org). Data were presented as frequencies (percentages) for categorical variables and means \pm standard deviation (SD) for continuous variables. Stratified analysis, interaction tests, and covariate screening were performed. Binary logistic regression analyses were used to assess the associations between HR (as a binary variable) and SUA concentration. SUA was evaluated as a continuous variable, a bi-level classification variable (Non-hyperuricemia: SUA $<7.0 \mathrm{mg} / \mathrm{dl}$ in males, SUA $<6.0 \mathrm{mg} / \mathrm{dl}$ in females; Hyperuricemia: SUA $\geq 7.0 \mathrm{mg} / \mathrm{dl}$ in males, SUA $\geq 6.0 \mathrm{mg} / \mathrm{dl}$ in females) and as quartiles (quartile $1:<4.4 \mathrm{mg} / \mathrm{dl}$; quartile 2: 4.4$5.3 \mathrm{mg} / \mathrm{dl}$; quartile $3: 5.3-6.4 \mathrm{mg} / \mathrm{dl}$; quartile $4: \geq 6.5 \mathrm{mg} /$ dl). The results were shown as odd ratios (OR) and $95 \%$ confidence intervals $(\mathrm{CI})$ with adjustment for major variables including age, sex, study center, treatment group, body mass index (BMI), SBP and DBP, triglycerides, fasting plasma glucose, creatinine. A two-tailed $P$ value of $<0.05$ was considered statistically significant.

\section{Results}

The present study included 12,966 subjects(mean age: $63.9 \pm 7.3$ years, range $44-81$ years, 5206 males and 7760 females, data not shown). Among them, 9848 (75.9\%) had $\mathrm{HR}$, the prevalence in males and females was $77.91 \%$ and $74.64 \%$, respectively. Grade 1 retinopathy was diagnosed in $58.80 \%(n=7624)$, grade 2 in $14.81 \%(n=1921)$, and grade 3 in $2.34 \%(n=303)$. Only three subjects were diagnosed as HR grade 4 , so these grade 4 subjects were merged with the grade 3 group for analysis.

Demographic and anthropometric characteristics and the laboratory results of the subjects are listed in Table 2. Subjects were divided into two groups: those without HR, the non-HR (NHR) group and those with HR, the HR group. There were significant differences in gender distribution $(P<0.001)$, systolic blood pressure (SBP; $P<0.001$ ), diastolic blood pressure (DBP; $P<0.001$ ), SUA $(P<0.001)$, folic acid $(P=0.044)$, creatinine $(P<0.001)$, study center location $(P<0.001)$ and consumption of alcohol $(P=0.001)$ in the two groups. Compared to NHR group, HR group had higher SBP, DBP, SUA, and creatinine levels. The mean value of SUA was $5.56 \mathrm{mg} / \mathrm{dl}$ and $5.36 \mathrm{mg} / \mathrm{dl}$ for the HR and NHR groups, respectively (Table 2).

SUA levels ranged from 1.70 to $16.23 \mathrm{mg} / \mathrm{dl}$ among all participants. Subjects were stratified into four groups according to their SUA quartiles. The percentage of HR prevalence was $73.38 \%$ for subjects in the first SUA quartile $(<4.4 \mathrm{mg} / \mathrm{dl}), 74.26 \%$ in the second SUA quartile $(4.4-5.3 \mathrm{mg} / \mathrm{dl}), 76.65 \%$ in the third SUA quartile $(5.3-6.4 \mathrm{mg} / \mathrm{dl})$, and $79.47 \%$ in the fourth SUA quartile $(\geq 6.5 \mathrm{mg} / \mathrm{dl}$; Table 3$)$. A positive trend was observed, with increased SUA quartiles, the prevalence of HR significantly increased $(P<0.001)$. To determine any difference in trend between men and women, data were stratified by gender. As shown in Table 3, male subjects had a higher prevalence of $H R$ than females in all SUA quartiles, thus the association between SUA and HR remained unaltered. Subjects were further divided into a non-hyperuricemia group $(n=10,007)$ and a hyperuricemia group $(n=2959)$ according to clinical SUA values defined previously. The hyperuricemia group had a higher prevalence of HR (79.48\%) than the non-hyperuricemia group $(74.97 \%)$. Collectively, these data suggested that increased SUA levels were associated with an increased prevalence of HR.

In order to accurately determine the relationship between SUA and HR, we conducted stratified analyses, interaction tests, and covariate screening. The screening criteria included any risk factor that produced a $>10 \%$ change in the regression coefficient after introduction into the basic model. The results show that triglyceride levels, creatinine levels, SBP, DBP, age, BMI, study center, and gender met the filter criteria. Binary logistic regression models were run after adjusting for confounding variables (gender, age, treatment group, study center, DM, BMI, creatinine levels, SBP, and DBP). The results showed that SUA remained significantly associated with $\mathrm{HR}(\mathrm{OR}=1.06$, 95\% CI: $1.02-1.10, P=0.002)$, indicating that every $1 \mathrm{mg} /$ $\mathrm{dl}$ increase in SUA concentration is associated with a $6 \%$ higher odds of retinopathy after adjusting for multiple confounders. For patients with SUA in the fourth quartile $(\geq 6.5 \mathrm{mg} / \mathrm{dl}$ ), a $1 \mathrm{mg} / \mathrm{dl}$ increase in SUA was significantly associated with a $21 \%$ higher odds of retinopathy $(\mathrm{OR}=1.21,95 \% \mathrm{CI}: 1.05-1.40, P=0.008)$ after adjusting for multiple confounders, when compared to patients with SUA in the 1 st quartile $(<4.4 \mathrm{mg} / \mathrm{dl})$. As a binary variable, compared with the non-hyperuricemia group, the OR for the hyperuricemia group was 1.18 (95\% CI: $1.05-1.33$, $P=0.004)$.

Data from $0.5 \%$ of the tails on either end of the distribution were deleted prior to performing a smooth curve fitting after adjusting for all variables. Figure 1 showed 
Table 2 Baseline characteristics of the study participants

\begin{tabular}{|c|c|c|c|c|}
\hline Characteristics & $\begin{array}{l}\text { Total } \\
(n=12,966)\end{array}$ & $\begin{array}{l}\text { NHR group } \\
(n=3118,24.05 \%)\end{array}$ & $\begin{array}{l}\text { HR group } \\
(n=9848,75.95 \%)\end{array}$ & $P$ value \\
\hline Age (years) & $63.90 \pm 7.30$ & $63.70 \pm 7.30$ & $63.96 \pm 7.30$ & 0.085 \\
\hline Gender & & & & $<0.001$ \\
\hline Male & $5206(40.20 \%)$ & 1150 (36.90\%) & $4056(41.20 \%)$ & \\
\hline Female & 7760 (59.80\%) & $1968(63.10 \%)$ & $5792(58.80 \%)$ & \\
\hline BMI $\left(\mathrm{kg} / \mathrm{m}^{2}\right)^{\mathrm{a}}$ & $25.10 \pm 3.81$ & $25.01 \pm 3.78$ & $25.14 \pm 3.82$ & 0.105 \\
\hline $\mathrm{SBP}(\mathrm{mmHg})$ & $135.80 \pm 17.48$ & $134.81 \pm 16.88$ & $136.11 \pm 17.65$ & $<0.001$ \\
\hline $\mathrm{DBP}(\mathrm{mmHg})$ & $82.25 \pm 10.89$ & $81.27 \pm 10.49$ & $82.56 \pm 10.99$ & $<0.001$ \\
\hline Uric Acid (mg/dl) & $5.51 \pm 1.49$ & $5.36 \pm 1.42$ & $5.56 \pm 1.51$ & $<0.001$ \\
\hline Creatinine $(\mu \mathrm{mol} / \mathrm{l})$ & $68.09 \pm 25.86$ & $66.39 \pm 21.99$ & $68.63 \pm 26.95$ & $<0.001$ \\
\hline Triglycerides (mmol/l) & $1.80 \pm 1.43$ & $1.76 \pm 1.34$ & $1.81 \pm 1.45$ & 0.086 \\
\hline Glucose $(\mathrm{mmol} / \mathrm{l})$ & $6.27 \pm 2.03$ & $6.24 \pm 1.87$ & $6.29 \pm 2.07$ & 0.261 \\
\hline Folic Acid (ng/ml) & $18.46 \pm 14.70$ & $17.99 \pm 13.37$ & $18.61 \pm 15.09$ & 0.044 \\
\hline DM & & & & 0.14 \\
\hline No & 10,089 (80.70\%) & $2466(81.60 \%)$ & $7623(80.40 \%)$ & \\
\hline Yes & $2412(19.30 \%)$ & $555(18.40 \%)$ & 1857 (19.60\%) & \\
\hline Study Center & & & $<0.001$ & \\
\hline Anqing & 2319 (17.90\%) & $420(13.50 \%)$ & 1899 (19.30\%) & \\
\hline Lianyungang & $10,647(82.10 \%)$ & $2698(86.50 \%)$ & 7949 (80.70\%) & \\
\hline Treatment Group & & & 0.985 & \\
\hline Enalapril only & $6531(50.40 \%)$ & $1571(50.40 \%)$ & 4960 (50.40\%) & \\
\hline Enalapril-Folic Acid & 6435 (49.60\%) & 1547 (49.60\%) & 4888 (49.60\%) & \\
\hline Smoker & & & & 0.15 \\
\hline Never & $8697(67.60 \%)$ & $2135(69.00 \%)$ & $6562(67.20 \%)$ & \\
\hline Former & 1404 (10.90\%) & $316(10.20 \%)$ & $1088(11.10 \%)$ & \\
\hline Current & $2756(21.40 \%)$ & $643(20.80 \%)$ & $2113(21.60 \%)$ & \\
\hline Alcohol Consumption & & & & 0.001 \\
\hline Never & $8733(70.80 \%)$ & $2184(73.40 \%)$ & 6549 (69.90\%) & \\
\hline Former & 838 (6.80\%) & $176(5.90 \%)$ & $662(7.10 \%)$ & \\
\hline Current & 2770 (22.40\%) & $615(20.70 \%)$ & 2155 (23.00\%) & \\
\hline
\end{tabular}

Abbreviations: SBP Systolic Blood Pressure, DBP Diastolic Blood ressure, DM diabetes mellitus, Treatment Group Enalapril only, Enalapril-Folic Acid, BMI body mass index

NHR group non-hypertensive retinopathy, HR group hypertensive retinopathy

${ }^{a}$ Calculated as weight in kilograms divided by height in meters squared

the resultant curve indicating that with increasing SUA levels, the risk of HR increases. We further explored the relationship between HR and SUA through stratified analysis where SUA was modeled as a continuous variable (Table 4). Interaction tests were performed to determine any impact of each stratified variable on the relationship between SUA and HR. ( $\mathrm{P} \leqslant 0.05$ was considered significant). No significant effect on SUA or HR was observed. The results indicated that there were no confounding factors between the variables. For women, a $1 \mathrm{mg} / \mathrm{dl}$ increase in SUA concentration was associated with a $9 \%$ higher odds of retinopathy $(\mathrm{OR}=1.09,95 \%$ CI: $1.04-1.14, P<0.001)$. For those under 60 years of age, a $1 \mathrm{mg} / \mathrm{dl}$ increase in SUA concentration was associated with an $11 \%$ higher odds of retinopathy $(\mathrm{OR}=1.11$, 95\% CI: $1.04-1.18, P=0.002)$. For Non-DM, a $1 \mathrm{mg} / \mathrm{dl}$ increase in SUA concentration was associated with an $5 \%$ higher odds of retinopathy $(\mathrm{OR}=1.05,95 \% \mathrm{CI}$ : 1.01-1.09, $P=0.028$ ) (Table 4).

Table 5 shows the results of SUA modeled in quartiles and as a binary variable. We observed a progressive and significant increase in the odds of retinopathy with SUA levels in the fourth quartile for females $(\mathrm{OR}=1.35,95 \% \mathrm{CI}: 1.12-1.63, P=0.002)$ and in the enalapril-folic acid treatment group (OR $=1.29,95 \%$ CI: $1.05-1.58, P=0.016)$. A similar trend was also seen 
Table 3 Prevalence of HR and the association between HR and SUA

\begin{tabular}{|c|c|c|c|c|c|c|c|c|}
\hline \multirow{3}{*}{ Serum Uric Acid (mg/dl) } & \multirow{3}{*}{$N$} & \multicolumn{3}{|c|}{ Prevalence of HR (\%) } & \multirow{2}{*}{\multicolumn{2}{|c|}{ Model 1}} & \multirow{2}{*}{\multicolumn{2}{|c|}{ Model 2}} \\
\hline & & \multirow[t]{2}{*}{$\begin{array}{l}\text { Total } \\
\end{array}$} & \multirow[t]{2}{*}{ Males } & \multirow[t]{2}{*}{ Females } & & & & \\
\hline & & & & & $\mathrm{OR}, 95 \% \mathrm{Cl}$ & $P$ & $\mathrm{OR}, 95 \% \mathrm{Cl}$ & $P$ \\
\hline Continuous variable & 12,966 & 75.95 & 77.90 & 74.60 & $1.10(1.07,1.13)$ & $<0.001$ & $1.06(1.02,1.10)$ & 0.002 \\
\hline \multicolumn{9}{|l|}{ Quartiles } \\
\hline Q1 (<4.4) & 3201 & 73.38 & 76.73 & 72.75 & 1 & & 1 & \\
\hline Q2 (4.4-5.3) & 3248 & 74.26 & 75.95 & 73.51 & $1.05(0.936,1.17)$ & 0.423 & $1.00(0.891,1.13)$ & 0.982 \\
\hline Q3 (5.3-6.4) & 3259 & 76.65 & 77.22 & 76.15 & $1.19(1.06,1.33)$ & 0.002 & $1.12(0.988,1.27)$ & 0.076 \\
\hline Q4 ( $\geq 6.5)$ & 3258 & 79.47 & 79.62 & 79.16 & $1.40(1.25,1.58)$ & $<0.001$ & $1.21(1.05,1.40)$ & 0.008 \\
\hline \multicolumn{9}{|l|}{ Binary Classification } \\
\hline Non-hyperuricemia & 10,007 & 74.97 & 77.00 & 73.60 & 1 & & 1 & \\
\hline Hyperuricemia & 2959 & 79.48 & 80.40 & 78.50 & $1.28(1.16,1.42)$ & $<0.001$ & $1.18(1.05,1.33)$ & 0.004 \\
\hline
\end{tabular}

Non-hyperuricemia SUA $<7.0 \mathrm{mg} / \mathrm{dl}$ in males and SUA $<6.0 \mathrm{mg} / \mathrm{dl}$ in females, hyperuricemia SUA $\geq 7.0 \mathrm{mg} / \mathrm{dl}$ in males and SUA $\geq 6.0 \mathrm{mg} / \mathrm{dl}$ in females Binary logistic regression models evaluating the association of serum uric acid (SUA) with hypertensive retinopathy (HR). $C l$ confidence interval $O R$ odds ratio Model 1: unadjusted

Model 2: adjusted for age, sex, study center, treatment group, body mass index(BMI), SBP, DBP, creatinine, triglycerides, and fasting plasma glucose if not stratified

in the second quartile of SBP and DBP. When compared with the non-hyperuricemia group, a $1 \mathrm{mg} / \mathrm{dl}$ increase in SUA concentration was associated with a $26 \%$ higher odds of retinopathy in females with hyperuricemia $(\mathrm{OR}=1.26$, 95\% CI: $1.09-1.46, P=0.002)$ and a $38 \%$ higher odds of retinopathy in those under 60 with hyperuricemia $(\mathrm{OR}=1.38$, 95\% CI:1.12-1.70, $P=0.003)$. Similarly, this trend was observed in the enalapril folic acid treatment group, the second quartile of SBP, the first and second quartile of DBP, and in patients without DM (Table 5).

\section{Discussion}

Our study was the first community-based epidemiologic study of HR in rural China and provided valuable information on the epidemiology of HR among a hypertensive population. The prevalence of HR in our study was $75.95 \%$, much higher than that reported in studies from Korea (61.3\%), and India (30.6\%) [8]. This may potentially reflected the higher incidence of hypertension in rural China and less concern and/or lack of knowledge of the complications from hypertension.

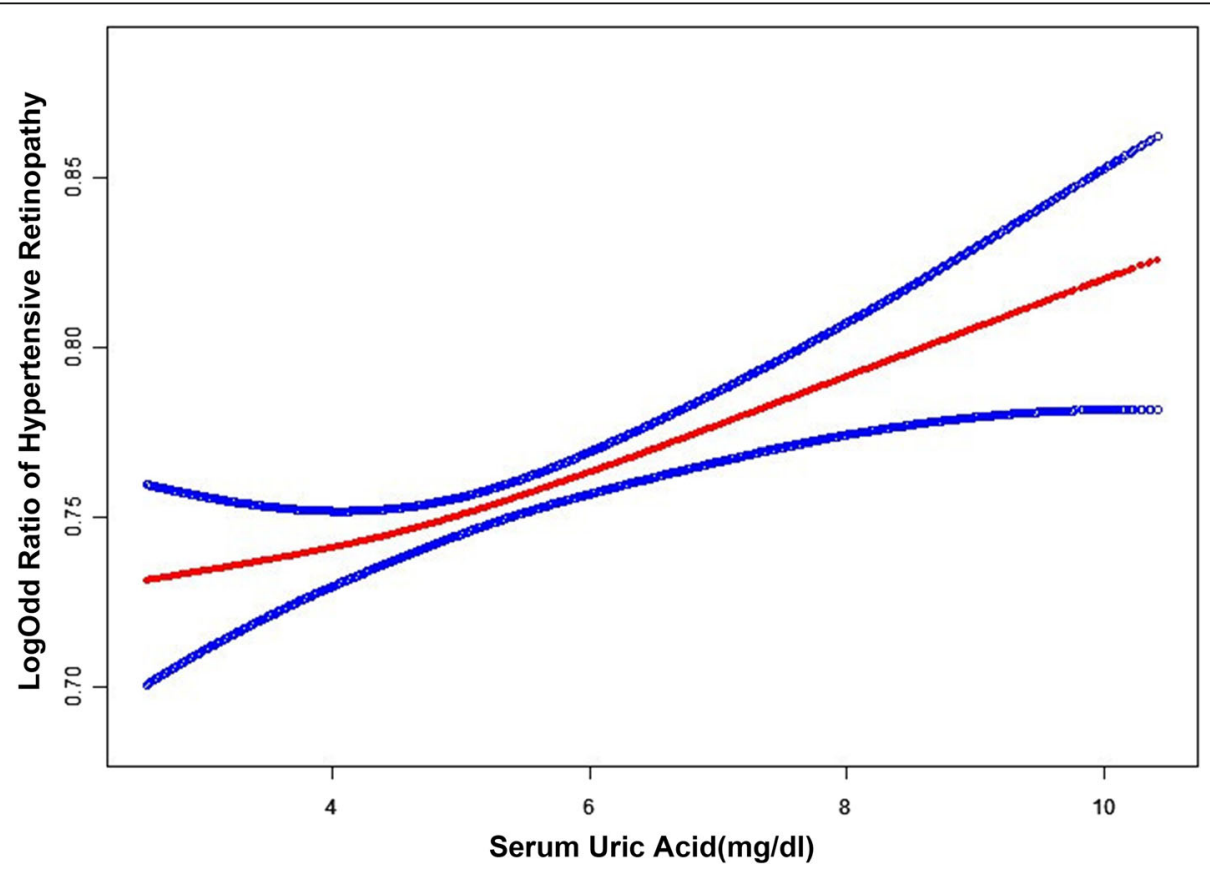

Fig. 1 Smooth curve fitting of hypertensive retinopathy and serum uric acid. Data from $0.5 \%$ of the tails on either end of the distribution were deleted prior to performing a smooth curve fitting after adjusting for all variables. With increasing serum uric acid (SUA) levels, the risk of hypertensive retinopathy (HR) increases. The red line represents the best-fit line; the blue lines are $95 \%$ confidence intervals 
Table 4 Stratified analysis of the association of SUA on the risk of hypertensive retinopathy (SUA as a continuous variable)

\begin{tabular}{|c|c|c|c|c|c|c|c|c|}
\hline \multirow[t]{2}{*}{ 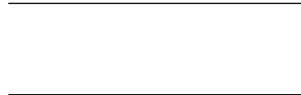 } & \multirow[t]{2}{*}{$n$} & \multirow[t]{2}{*}{ Events } & \multirow[t]{2}{*}{$\%$} & \multicolumn{2}{|l|}{ Model 1} & \multicolumn{2}{|l|}{ Model 2} & \multirow{2}{*}{$\begin{array}{l}P \text { value for } \\
\text { interaction }\end{array}$} \\
\hline & & & & OR $(95 \% \mathrm{Cl})$ & $P$ & OR $(95 \% \mathrm{Cl})$ & $P$ & \\
\hline Gender & & & & & & & & 0.122 \\
\hline Male & 5206 & 4056 & 77.91 & $1.07(1.02,1.11)$ & 0.005 & $1.02(0.96,1.07)$ & 0.593 & \\
\hline Female & 7760 & 5792 & 74.64 & $1.10(1.06,1.15)$ & $<0.001$ & $1.09(1.04,1.14)$ & $<0.001$ & \\
\hline Age (years) & & & & & & & & 0.129 \\
\hline$<60$ & 8846 & 6759 & 76.41 & $1.14(1.08,1.20)$ & $<0.001$ & $1.11(1.04,1.18)$ & 0.002 & \\
\hline$\geq 60$ & 4120 & 3089 & 74.98 & $1.08(1.04,1.11)$ & $<0.001$ & $1.03(0.99,1.08)$ & 0.154 & \\
\hline Treatment Group & & & & & & & & 0.267 \\
\hline Enalapril only & 6531 & 4960 & 75.95 & $1.08(1.04,1.12)$ & $<0.001$ & $1.05(1.00,1.10)$ & 0.076 & \\
\hline Enalapril-Folic Acid & 6435 & 4888 & 75.96 & $1.11(1.07,1.16)$ & $<0.001$ & $1.07(1.02,1.13)$ & 0.010 & \\
\hline $\mathrm{SBP}(\mathrm{mmHg})$ & & & & & & & & 0.535 \\
\hline$<127.0$ & 4163 & 3088 & 74.18 & $1.11(1.06,1.16)$ & $<0.001$ & $1.08(1.01,1.14)$ & 0.019 & \\
\hline $127.0 \leq \mathrm{SBP}<141.3$ & 4204 & 3197 & 76.05 & $1.12(1.07,1.18)$ & $<0.001$ & $1.09(1.03,1.16)$ & 0.006 & \\
\hline$\geq 141.3$ & 4448 & 3447 & 77.5 & $1.07(1.02,1.12)$ & 0.008 & $1.01(0.95,1.07)$ & 0.846 & \\
\hline $\mathrm{DBP}(\mathrm{mmHg})$ & & & & & & & & 0.083 \\
\hline$<78.0$ & 4145 & 3071 & 74.09 & $1.10(1.05,1.15)$ & $<0.001$ & $1.06(1.00,1.12)$ & 0.069 & \\
\hline$\geq 78.0,<86.5$ & 4392 & 3303 & 75.2 & $1.14(1.08,1.20)$ & $<0.001$ & $1.09(1.03,1.16)$ & 0.005 & \\
\hline$\geq 86.5$ & 4278 & 3358 & 78.49 & $1.05(0.99,1.10)$ & 0.083 & $1.02(0.95,1.08)$ & 0.618 & \\
\hline $\mathrm{DM}$ & & & & & & & & 0.834 \\
\hline No & 10,089 & 7623 & 75.56 & $1.10(1.07,1.14)$ & $<0.001$ & $1.05(1.01,1.09)$ & 0.028 & \\
\hline Yes & 2412 & 1857 & 76.99 & $1.09(1.02,1.15)$ & 0.009 & $1.07(0.99,1.16)$ & 0.077 & \\
\hline
\end{tabular}

Abbreviations: SBP Systolic Blood Pressure, DBP Diastolic Blood Pressure, DM diabetes mellitus, Treatment Group Enalapril only, Enalapril-Folic Acid Binary logistic regression models evaluating the association of serum uric acid(SUA) with hypertensive retinopathy(HR). $C l$ confidence interval, OR odds ratio Model 1: unadjusted

Model 2: adjusted for age, sex, study center, treatment group, body mass index(BMI), SBP, DBP, creatinine, triglycerides, and fasting plasma glucose if not stratified

Identification of clinical features that could be used to predict the development and progression of retinopathy is of crucial importance for hypertensive patients.

In recent years, numerous studies have indicated a relationship between uric acid and ocular disease. Some ocular manifestations of gout, which is characterized by a rise in SUA, have been reported, including corneal uric acid crystals, band keratopathy, increased intraocular pressure, asteroid hyalosis, conjunctival injection, and uveitis [20]. Patients with normal-tension glaucoma (NTG) have higher SUA levels than controls [21]. Retinal vein occlusion (RVO) in both eyes often accompanied with hyperuricemia [22]. In addition, uric acid also played an important role in diabetic retinopathy (DR). A 3 -year prospective study in patients with Type $2 \mathrm{DM}$ indicated that SUA concentration was associated with an increase in the severity of DR [23]. SUA may also be involved in the pathogenesis and progression of DR [24]. Researches all above presented the negative influence on eyes. However, some studies maintained that the effect of uric acid was that of an antioxidant, may protect the retina from oxidative damage. Morsal et al. [25] supported the concept that elevated SUA levels may provide a therapeutic approach for the treatment of ARMD. Several studies have established important relationships between low uric acid and neuromyelitis optica [26, 27]. Low SUA appeared to precede the incidence of DR, and that SUA declined further as the disease progresses [28]. According to previous literature, it was observed that although the association between HR and SUA was somehow inconsistent, most results of researches proved more strong evidence that SUA as a destructive factor and aggravated ocular disease, including normal-tension glaucoma (NTG), retinal vein occlusion (RVO) and diabetic retinopathy (DR) [21-24]. In our study, SUA concentration was significantly associated with HR; the results supported the adverse effect of uric acid on HR.

The prevalence of hyperuricemia in hypertensive patients was reported between around $20 \%-50 \%[29,30]$. Significant epidemiological evidence showed that uric acid might be associated with hypertension [31]. An elevation in SUA was associated with an increased risk for the development of hypertension [32]. Therefore, we hypothesized uric acid tend to play as a provident in pathogenesis of HR and promote its development and progression. 
Table 5 Stratified analysis of the association of SUA on the risk of hypertensive retinopathy (SUA quartiles and as binary variable)

\begin{tabular}{|c|c|c|c|c|c|c|c|c|}
\hline \multirow[t]{2}{*}{ Variable } & \multicolumn{8}{|c|}{ SUAmg/dl (OR, 95\% Cl, $P$ value) } \\
\hline & Q1 & Q2 & Q3 & Q4 & $\begin{array}{l}P \text { value for } \\
\text { interaction }\end{array}$ & Non-hyperuricemia & Hyperuricemia & $\begin{array}{l}P \text { value for } \\
\text { interaction }\end{array}$ \\
\hline Gender & & & & & 0.297 & & & 0.235 \\
\hline Male & 1 & $\begin{array}{l}0.93(0.72,1.22) \\
0.616\end{array}$ & $\begin{array}{l}0.96(0.74,1.23) \\
0.721\end{array}$ & $\begin{array}{l}1.00(0.77,1.29) \\
0.970\end{array}$ & & 1 & $\begin{array}{l}1.06(0.88,1.27) \\
0.531\end{array}$ & \\
\hline Female & 1 & $\begin{array}{l}1.01(0.89,1.15) \\
0.877\end{array}$ & $\begin{array}{l}1.19(1.03,1.38) \\
0.022\end{array}$ & $\begin{array}{l}1.35(1.12,1.63) \\
0.002\end{array}$ & & 1 & $\begin{array}{l}1.26(1.09,1.46) \\
0.002\end{array}$ & \\
\hline Age (years) & & & & & 0.026 & & & 0.149 \\
\hline$<60$ & 1 & $\begin{array}{l}1.10(0.95,1.27) \\
0.197\end{array}$ & $\begin{array}{l}1.12(0.96,1.31) \\
0.149\end{array}$ & $\begin{array}{l}1.19(1.00,1.41) \\
0.054\end{array}$ & & 1 & $\begin{array}{l}1.38(1.12,1.70) \\
0.003\end{array}$ & \\
\hline$\geq 60$ & 1 & $\begin{array}{l}0.84(0.70,1.02) \\
0.084\end{array}$ & $\begin{array}{l}1.12(0.91,1.39) \\
0.277\end{array}$ & $\begin{array}{l}1.28(1.00,1.65) \\
0.054\end{array}$ & & 1 & $\begin{array}{l}1.09(0.95,1.26) \\
0.197\end{array}$ & \\
\hline Treatment Group & & & & & 0.302 & & & 0.0301 \\
\hline Enalapril only & 1 & $\begin{array}{l}1.04(0.89,1.23) \\
0.603\end{array}$ & $\begin{array}{l}1.12(0.94,1.33) \\
0.215\end{array}$ & $\begin{array}{l}1.15(0.94,1.40) \\
0.172\end{array}$ & & 1 & $\begin{array}{l}1.05(0.90,1.23) \\
0.509\end{array}$ & \\
\hline Enalapril-Folic Acid & 1 & $\begin{array}{l}0.96(0.81,1.13) \\
0.604\end{array}$ & $\begin{array}{l}1.12(0.94,1.34) \\
0.198\end{array}$ & $\begin{array}{l}1.29(1.05,1.58) \\
0.016\end{array}$ & & 1 & $\begin{array}{l}1.34(1.13,1.58) \\
<0.001\end{array}$ & \\
\hline $\mathrm{SBP}(\mathrm{mmHg})$ & & & & & 0.671 & & & 0.165 \\
\hline$<127.0$ & 1 & $\begin{array}{l}1.04(0.85,1.28) \\
0.715\end{array}$ & $\begin{array}{l}1.19(0.96,1.48) \\
0.107\end{array}$ & $\begin{array}{l}1.21(0.95,1.54) \\
0.128\end{array}$ & & 1 & $\begin{array}{l}1.20(0.99,1.46) \\
0.070\end{array}$ & \\
\hline$\geq 127.0,<141.3$ & 1 & $\begin{array}{l}0.93(0.76,1.14) \\
0.469\end{array}$ & $\begin{array}{l}1.08(0.87,1.33) \\
0.499\end{array}$ & $\begin{array}{l}1.38(1.07,1.77) \\
0.013\end{array}$ & & 1 & $\begin{array}{l}1.35(1.10,1.66) \\
0.004\end{array}$ & \\
\hline$\geq 141.3$ & 1 & $\begin{array}{l}1.04(0.85,1.26) \\
0.731\end{array}$ & $\begin{array}{l}1.09(0.88,1.35) \\
0.449\end{array}$ & $\begin{array}{l}1.08(0.85,1.38) \\
0.533\end{array}$ & & 1 & $\begin{array}{l}1.03(0.85,1.25) \\
0.787\end{array}$ & \\
\hline $\mathrm{DBP}(\mathrm{mmHg})$ & & & & & 0.326 & & & 0.182 \\
\hline$<78.0$ & 1 & $\begin{array}{l}0.99(0.81,1.20) \\
0.893\end{array}$ & $\begin{array}{l}1.17(0.95,1.46) \\
0.143\end{array}$ & $\begin{array}{l}1.10(0.86,1.39) \\
0.458\end{array}$ & & 1 & $\begin{array}{l}1.22(1.00,1.49) \\
0.047\end{array}$ & \\
\hline$\geq 78.0,<86.5$ & 1 & $\begin{array}{l}1.06(0.88,1.29) \\
0.523\end{array}$ & $\begin{array}{l}1.17(0.95,1.43) \\
0.141\end{array}$ & $\begin{array}{l}1.43(1.12,1.83) \\
0.004\end{array}$ & & 1 & $\begin{array}{l}1.23(1.01,1.51) \\
0.039\end{array}$ & \\
\hline$\geq 86.5$ & 1 & $\begin{array}{l}0.92(0.74,1.15) \\
0.473\end{array}$ & $\begin{array}{l}0.99(0.79,1.24) \\
0.902\end{array}$ & $\begin{array}{l}1.09(0.85,1.41) \\
0.485\end{array}$ & & 1 & $\begin{array}{l}1.08(0.89,1.32) \\
0.445\end{array}$ & \\
\hline $\mathrm{DM}$ & & & & & 0.998 & & & 0.941 \\
\hline No & 1 & $\begin{array}{l}0.98(0.86,1.11) \\
0.732\end{array}$ & $\begin{array}{l}1.10(0.96,1.27) \\
0.181\end{array}$ & $\begin{array}{l}1.15(0.98,1.35) \\
0.097\end{array}$ & & 1 & $\begin{array}{l}1.16(1.02,1.32) \\
0.028\end{array}$ & \\
\hline Yes & 1 & $\begin{array}{l}1.05(0.80,1.38) \\
0.716\end{array}$ & $\begin{array}{l}1.20(0.90,1.60) \\
0.209\end{array}$ & $\begin{array}{l}1.34(0.97,1.85) \\
0.073\end{array}$ & & 1 & $\begin{array}{l}1.21(0.93,1.57) \\
0.148\end{array}$ & \\
\hline
\end{tabular}

Abbreviations: SBP Systolic Blood Pressure, DBP Diastolic Blood Pressure, $\mathrm{Cl}$ confidence interval, $O R$ odds ratio

Q1: $<4.4 \mathrm{mg} / \mathrm{dl}$; Q2: 4.4-5.3 mg/dl; Q3: 5.3-6.4 mg/dl; Q4: $\geq 6.5 \mathrm{mg} / \mathrm{dl}$; DM,diabetes mellitus; Treatment Group: Enalapril only, Enalapril-Folic Acid

Non-hyperuricemia: SUA $<7.0 \mathrm{mg} / \mathrm{dl}$ in males and SUA $<6.0 \mathrm{mg} / \mathrm{dl}$ in females; hyperuricemia: SUA $\geq 7.0 \mathrm{mg} / \mathrm{dl}$ in males and SUA $\geq 6.0 \mathrm{mg} / \mathrm{dl}$ in females

The role of uric acid as a mediator of vascular damage is not a new idea but has only recently gained widespread acceptance [29]. Increased levels of SUA can lead to endothelial cell dysfunction, which is an important step in the development of atherosclerosis, via nitric oxide synthase and stimulation of vascular smooth muscle cell proliferation [32]. Rat models of hyperuricemia suggest that hyperuricemia leads to hypertension in a stepwise fashion. In the first phase, uric acid-dependent activation of the renin-angiotensin system and down regulation of nitric oxide (NO) production, led to vasoconstriction. At this stage, uric acid reduction results in vascular relaxation and improved blood pressure. The second phase, which develops over time, is characterized by uric acid-mediated arteriolosclerosis. This process is not reversed by later reduction of uric acid, and causes permanent sodiumsensitive hypertension [33]. Retinal vasculature and other target organs share similar anatomical features and physiological properties. The effect of SUA on the systemic blood vessels also affects the retinal vascular bed. HR can be divided into four stages according to physiology, vasoconstriction, sclerosis, exudation and complications [34]. High blood pressure stimulates the constriction of vessels, and long-term vasoconstriction causes vasospasm and vascular endothelium hypoxia-ischemia. These processes culminate in vascular smooth muscle cell 
proliferation, vascular wall thickening and vessel stenosis [35]. Uric acid may have a similar effect as high blood pressure on vessels and prompts the vascular sclerosis in union.

We observed interesting phenomena that SUA may have a greater influence in women and non-DM. Compared to men, women have lower SUA levels and fewer cardiovascular risk factors [36]. Much experimental and epidemiological evidence suggested that estrogen exert a vascular protective function and may have beneficial effects on endothelial function and atherosclerosis, raising the possibility of sex differences in arterial remodeling [37]. However, many studies indicated that SUA had greater influence on women [38, 39]. Recent studies showed a relationship between SUA and coronary atherosclerosis in women only $[40,41]$. In patients with hyperuricemia, women have higher risk of left ventricular hypertrophy than men [42]. Similar phenomenon also appeared in our study, for women, a $1 \mathrm{mg} / \mathrm{dl}$ increase in SUA concentration was associated with a 9\% higher odds of retinopathy, while the corresponding values were not significant for men. The hormonal changes may be the key point. Hormonal changes after menopause increased the risk for cardiovascular diseases [43]. Sudden withdrawal of estrogen affected developing endothelial dysfunction in menopause [44]. In our study, subjects were between 44 and 81 years old. Women in this study had either reached perimenopause, were in menopause or were post-menopausal, and all had reduced protective effects of estrogen, making them more vulnerable to oxidants. This may be a possible explanation for the significant association between SUA and HR in women in our cohort. In addition, Iemolo et al. studied sex differences in carotid plaque and stenosis, and concluded that women have more stenosis but fewer plaques than men, suggesting that differences in sex hormones may affect remodeling of atherosclerosis. So we inferred that there was another possibility that women may display significant differences in the appearance of HR. Generally, in the evaluation of $H R$, stenosis was emphasized rather than atherosclerosis, which may partly explain why women have a higher rate of HR.

For the non-DM group, a $1 \mathrm{mg} / \mathrm{dl}$ increase in SUA concentration was associated with a $5 \%$ higher odds of retinopathy while the odds were not significantly changed in the DM group. This result seemed to contradict previous studies, indicating that DR was associated with SUA. Uric acid, high blood pressure and high blood glucose all have destructive effect on vessels $[45,46]$. Typical early retinopathy signs of DM and hypertension share many morphological and pathophysiological similarities [47]. We concluded that glucose may play a more important role in the DM group in our cohort than uric acid, and the subjects in the non-DM group were more sensitive to uric acid.

Our study was limited in the following aspects. First, the CSPPT participants were rural Chinese, thus the generalizability of our findings to other populations requires caution. Second, more than 30\% were excluded because of the lack of photographic material or SUA analysis, this group may have potential influence on our result, however, we thought this group did not differed from the total population in terms of the main variables of interest so the influence was minor. Third, there were a limited number of subjects with grade 3 and grade 4 HR. Fourth, there were lacks of assessments on other hypertension related ocular diseases, which may also be affected by SUA. Fifth, the non-mydriatic fundus photography was imperfect. Due to the study was a large community-based trial, we were not allowed to do dilated eye examination to every person. Hypertension mainly affected retinal arteries and their first or second branches, and it caused lesions distributed peripapillary, which can be covered by non-mydriatic fundus photographs mostly, although we may not be able to catch changes of peripheral fundus. Many other studies about HR also adopted non-mydriatic retinal photograph or performed direct ophthalmoscopy without mydriasis $[6,48]$. Besides, fundus examination was not free from subjectivity, and the KWB classification system was still controversial. Finally, the study lacked any long-term follow up investigation into the impact of uric acid. In order to provide an in-depth examination of the relationship between SUA and HR, a longer term follow-up study including more detailed factors is required.

\section{Conclusion}

In conclusion, this cross-sectional study demonstrated that SUA concentration was positively associated with odds of HR, every $1 \mathrm{mg} / \mathrm{dl}$ increase in SUA concentration was associated with a $6 \%$ higher odds of retinopathy. We emphasized the effect of metabolic factors on HR and speculated that SUA provided useful information to physicians for the timing of funduscopic examinations in hypertensive. Further elucidation of the underlying mechanism that SUA promotes HR may need further study. Whether SUA lowing can reduce a risk of HR still need deeper discussion and clinical trials.

\section{Acknowledgements \\ We acknowledge Xiping Xu,Wenbin Yang, Xianhui Qin, and Yun Song for providing statistical support.}

Availability of data and materials

Details of China Stroke Primary Prevention Trial (CSPPT) have been described elsewhere (http://clinicaltrials.gov/ct2/show/NCT00794885). The data that support the findings of this study are available from the corresponding author upon reasonable request. 


\section{Funding}

This work was supported by the China Stroke Primary Prevention Trial (CSPPT, clinicaltrials.gov identifier: NCT00794885), (http://clinicaltrials.gov/ ct2/show/NCT00794885) and National Natural Science Foundation of China. (No. 81470650)

\section{Authors' contributions}

Professor LY, Professor XPX and Professor YH were general leaders of our team. Professor LY and Professor YH as corresponding authors, were responsible for project design and funding. Professor $L Y$ also checked the article writing. BYW FFH, GFT, JPL, RFL, XHQ, YZ collected epidemiologic data. XPG, YDZ, and YP took pictures. HCS, JZ, JL and LZ perform the classification of fundus photographs. KS, WBY, XLC, YM attributed to data analysis, XLC was a major contributor in writing the manuscript. All authors read and approved the final manuscript.

\section{Competing interests}

The authors declare that they have no competing interests.

\section{Consent for publication}

Not applicable.

\section{Ethics approval and consent to participate}

The study complied with the Helsinki Declaration and was approved by the Ethics Committee of the Institute of Biomedicine, Anhui Medical University, Hefei, China (FWA assurance number FWA00001263). All participants provided written informed consent. CSPPT study was a large communitybased, randomized, multicenter, double blind, and actively controlled trial designed to evaluate whether combination therapy with enalapril maleate and folic acid tablets combined were more effective in preventing stroke in Chinese adults with hypertension than enalapril maleate alone.

\section{Publisher's Note}

Springer Nature remains neutral with regard to jurisdictional claims in published maps and institutional affiliations.

\section{Author details \\ ${ }^{1}$ Department of Ophthalmology, Key Laboratory of Vision Loss and Restoration, Ministry of Education, Peking University First Hospital, No.8 Xishiku Street, Xicheng District, Beijing 100034, China. ${ }^{2}$ Department of Tongren Hospital, Beijing 100005, China. ${ }^{3}$ Department of Epidemiology and Biostatistics, School of Public Health, Anhui Medical University, Hefei, Anhui 230032, China. ${ }^{4}$ Department of Cardiology, Peking University First Hospital, No. 8 Xishiku Street, Xicheng District, Beijing 100034, China. ${ }^{5}$ National Clinical Research Study Center for Kidney Disease; State Key Laboratory for Organ Failure Research; Renal Division, Nanfang Hospital, Southern Medical University, Guangzhou 510515, China. ${ }^{6}$ School of Health Administration, Anhui University, Hefei 230039, China. ${ }^{7}$ Department of Ophthalmology, The First Affiliated Hospital of Anhui Medical University, Hefei, Anhui 230032, China.}

\section{Received: 9 February 2017 Accepted: 15 May 2017}

\section{Published online: 02 June 2017}

\section{References}

1. Lewington S, Lacey B, Clarke R, Guo Y, Kong XL, Yang L, et al. The Burden of Hypertension and Associated Risk for Cardiovascular Mortality in China. JAMA Intern Med. 2016;176:524-32. doi:10.1001/jamainternmed.2016.0190.

2. Abbassi S, Thinda S, Morse LS. Hypertensive retinopathy, choroidopathy, and optic neuropathy. Jama Ophthalmol. 2015;133:e151494. doi:10.1001/ jamaophthalmol.2015.1494

3. Stryjewski TP, Papakostas TD, Vavvas D. Proliferative Hypertensive Retinopathy. Jama Ophthalmol. 2016;134:345-6. doi:10.1001/ jamaophthalmol.2015.5583.

4. Cheung CY, Ikram MK, Sabanayagam C, Wong TY. Retinal microvasculature as a model to study the manifestations of hypertension. Hypertension. 2012; 60:1094-103. doi:10.1161/HYPERTENSIONAHA.111.189142.

5. Kabedi NN, Mwanza JC, Lepira FB, Kayembe TK, Kayembe DL. Hypertensive retinopathy and its association with cardiovascular, renal and cerebrovascular morbidity in Congolese patients. Cardiovasc J Afr. 2014:25: 228-32. doi:10.5830/CVJA-2014-045
6. $\quad$ Ong YT, Wong TY, Klein R, Klein BE, Mitchell P, Sharrett AR, et al. Hypertensive retinopathy and risk of stroke. Hypertension. 2013;62:706-11. doi:10.1161/ HYPERTENSIONAHA.113.01414.

7. Bakalli A, Kocinaj D, Bakalli A, Krasniqi A. Relationship of hypertensive retinopathy to thoracic aortic atherosclerosis in patients with severe arterial hypertension. Clin Exp Hypertens. 2011;33:89-94. doi:10.3109/10641963. 2010.503307.

8. Shantha GP, Srinivasan Y, Kumar AA, Salim S, Prabakhar S, Rajan AG, et al. Can retinal changes predict coronary artery disease in elderly hypertensive patients presenting with angina? Am J Emerg Med. 2010;28:617-21. doi:10.1016/j.ajem.2009.04.007.

9. Kim GH, Youn HJ, Kang S, Choi YS, Moon Jl. Relation between grade II hypertensive retinopathy and coronary artery disease in treated essentia hypertensives. Clin Exp Hypertens. 2010;32:469-73. doi:10.3109/10641963. 2010.496515.

10. Karaca M, Coban E, Ozdem S, Unal M, Salim O, Yucel O. The association between endothelial dysfunction and hypertensive retinopathy in essential hypertension. Med Sci Monit. 2014;20:78-82. doi:10.12659/MSM.889659.

11. Karaca M, Coban E, Felek R, Unal M. The association of oxidative stress with hypertensive retinopathy. Clin Exp Hypertens. 2013;35:16-9. doi:10.3109/ 10641963.2012 .685535

12. Coban E, Nizam I, Topal C, Akar Y. The association of low-grade systemic inflammation with hypertensive retinopathy. Clin Exp Hypertens. 2010;32: 528-31. doi:10.3109/10641963.2010.496519.

13. Abbasian M, Ebrahimi H, Delvarianzadeh M, Norouzi P, Fazli M. Association between serum uric acid (SUA) levels and metabolic syndrome (MetS) components in personnel of Shahroud University of Medical Sciences. Diabetes Metab Syndr. 2016; doi:10.1016/j.dsx.2016.01.003.

14. Grayson PC, Kim SY, LaValley M, Choi HK. Hyperuricemia and Incident Hypertension: A Systematic Review and Meta-Analysis. Arthritis Care Res (Hoboken). 2011;63:102-10. doi:10.1002/acr.20344.

15. Wang J, Qin T, Chen J, Li Y, Wang L, Huang H, et al. Hyperuricemia and risk of incident hypertension: a systematic review and meta-analysis of observational studies. PLoS One. 2014:9:e114259. doi:10.1371/journal.pone.0114259.

16. Sharon Y, Schlesinger N. Beyond Joints: a Review of Ocular Abnormalities in Gout and Hyperuricemia. Curr Rheumatol Rep. 2016;18:37. doi:10.1007/s11926016-0586-8.

17. Li LX, Lu JX, Shuai HP, Xia HF, Zhang R, Wang JW, et al. Decreased urine uric acid excretion is associated with diabetic retinopathy but not with lower limb atherosclerosis in hospitalized patients with type 2 diabetes. Atherosclerosis. 2015;242:13-8. doi:10.1016/j.atherosclerosis.2015.06.051.

18. Huo Y, Li J, Qin X, Huang Y, Wang X, Gottesman RF, et al. Efficacy of folic acid therapy in primary prevention of stroke among adults with hypertension in China: the CSPPT randomized clinical trial. JAMA. 2015;313: 1325-35. doi:10.1001/jama.2015.2274

19. Keith NM, Wagener HP, Barker NW. Some different types of essential hypertension: their course and prognosis. Am J Med Sci. 1974;268:336-45.

20. Yulek F, Cagil N, Orhan N, Midillioglu IK, Erten S, Simsek S. Gout attack with unusual ocular complications. Rheumatol Int. 2009:29:557-9. doi:10.1007/ s00296-008-0736-z.

21. Yuki K, Murat D, Kimura I, Ohtake Y, Tsubota K. Reduced-serum vitamin C and increased uric acid levels in normal-tension glaucoma. Graefes Arch Clin Exp Ophthalmol. 2010;248:243-8. doi:10.1007/s00417-009-1183-6.

22. Darrelmann O, Kreissig I, Richard G. Bilateral retinal vein occlusions and general risk factors. Klin Monatsbl Augenheilkd. 1985:186:39-42. doi:10.1055/s-2008-1050871.

23. Lee JJ, Yang $\mathrm{H}$, Kuo HK, Chung MS, Chen YJ, Chen $\mathrm{CH}$, et al. Serum uric acid concentration is associated with worsening in severity of diabetic retinopathy among type 2 diabetic patients in Taiwan-a 3-year prospective study. Diabetes Res Clin Pract. 2014;106:366-72. doi:10.1016/j.diabres.2014.07.027.

24. Krizova L, Kalousova M, Kubena A, Benakova H, Zima T, Kovarik Z, et al. Increased uric acid and glucose concentrations in vitreous and serum of patients with diabetic macular oedema. Ophthalmic Res. 2011;46:73-9. doi: $10.1159 / 000322994$

25. Mehryar M, Farvardin M, Hosseini H, Aslani M. Potential role of uric acid in the molecular pathogenesis of age-related macular degeneration. Med Hypotheses. 2006;66:793-5. doi:10.1016/j.mehy.2005.10.014.

26. Peng $F$, Yang $Y$, Liu J, Jiang $Y$, Zhu $C$, Deng $X$, et al. Low antioxidant status of serum uric acid, bilirubin and albumin in patients with neuromyelitis optica. Eur J Neurol. 2012;19:277-83. doi:10.1111/j.14681331.2011.03488.x. 
27. Knapp CM, Constantinescu CS, Tan JH, McLean R, Cherryman GR, Gottlob I. Serum uric acid levels in optic neuritis. Mult Scler. 2004;10:278-80.

28. Yanko L, Goldbourt U, Michaelson IC, Shapiro A, Yaari S. Prevalence and 15year incidence of retinopathy and associated characteristics in middle-aged and elderly diabetic men. Br J Ophthalmol. 1983;67:759-65.

29. Edwards NL. The role of hyperuricemia in vascular disorders. Curr Opin Rheumatol. 2009;21:132-7. doi:10.1097/BOR.0b013e3283257b96.

30. Cannon PJ, Stason WB, Demartini FE, Sommers SC, Laragh JH. Hyperuricemia in primary and renal hypertension. N Engl J Med. 1966;275: 457-64. doi:10.1056/NEJM196609012750902.

31. Yang T, Chu CH, Bai CH, You SL, Chou YC, Hwang LC, et al. Uric acid concentration as a risk marker for blood pressure progression and incident hypertension: a Chinese cohort study. Metabolism. 2012;61:1747-55. doi:10.1016/j.metabol.2012.05.006.

32. Mellen PB, Bleyer AJ, Erlinger TP, Evans GW, Nieto FJ. Wagenknecht LEet al. Serum uric acid predicts incident hypertension in a biethnic cohort: the atherosclerosis risk in communities study. Hypertension. 2006;48:1037-42. doi:10.1161/01.HYP.0000249768.26560.66.

33. Feig DI. The role of uric acid in the pathogenesis of hypertension in the young. J Clin Hypertens (Greenwich). 2012;14:346-52. doi:10.1111/j.17517176.2012.00662.x.

34. Wong TY, Mitchell P. The eye in hypertension. Lancet. 2007:369:425-35. doi:10.1016/S0140-6736(07)60198-6.

35. Avendano MS, Martinez-Revelles S, Aguado A, Simoes MR, Gonzalez-Amor M, Palacios $\mathrm{R}$, et al. Role of COX-2-derived PGE2 on vascular stiffness and function in hypertension. Br J Pharmacol. 2016;173:1541-55. doi:10.1111/bph.13457.

36. Li Z, Meng L, Huang Z, Cui L, Li W, Gao J, et al. Ideal Cardiovascular Health Metrics and Incident Hyperuricemia. Arthritis Care Res (Hoboken). 2016;68: 660-6. doi:10.1002/acr.22830

37. lemolo F, Martiniuk A, Steinman DA, Spence JD. Sex differences in carotid plaque and stenosis. Stroke. 2004;35:477-81. doi:10.1161/01.STR.0000110981. 96204.64.

38. Sabio JM, Vargas-Hitos JA, Mediavilla JD, Navarrete-Navarrete N, ZamoraPosadas M, Perez-Vicente S, et al. Correlation of asymptomatic hyperuricaemia and serum uric acid levels with arterial stiffness in women with systemic lupus erythematosus without clinically evident atherosclerotic cardiovascular disease. Lupus. 2010;19:591-8. doi:10.1177/0961203309355301.

39. Kawamoto R, Tabara Y, Kohara K, Kusunoki T, Abe M, Miki T. Synergistic influence of age and serum uric acid on blood pressure among community-dwelling Japanese women. Hypertens Res. 2013;36:634-8. doi:10.1038/hr.2013.5.

40. Zhang JW, He L, Cao SJ, Yang Q, Yang SW, Zhou YJ. Association of serum uric acid and coronary artery disease in premenopausal women. PLoS One. 2014;9:e106130. doi:10.1371/journal.pone.0106130.

41. Sun Y, Yu X, Zhi Y, Geng S, Li H, Liu T, et al. A cross-sectional analysis of the relationship between uric acid and coronary atherosclerosis in patients with suspected coronary artery disease in China. BMC Cardiovasc Disord. 2014;14 101. doi:10.1186/1471-2261-14-101.

42. Yu S, Guo X, Yang H, Sun Y. Combination of hyperuricemia and metabolic syndrome is an independent and powerful predictor for left ventricular hypertrophy in rural Chinese. Ann Endocrinol (Paris). 2015;76:264-71. doi:10.1016/j.ando.2015.01.002.

43. Mijatovic V, van der Mooren MJ, Stehouwer CD, Netelenbos JC, Kenemans P. Postmenopausal hormone replacement, risk estimators for coronary artery disease and cardiovascular protection. Gynecol Endocrinol. 1999;13:130-44.

44. Rubanyi GM, Johns A, Kauser K. Effect of estrogen on endothelial function and angiogenesis. Vasc Pharmacol. 2002;38:89-98.

45. Kanellis J, Kang DH. Uric acid as a mediator of endothelial dysfunction, inflammation, and vascular disease. Semin Nephrol. 2005;25:39-42.

46. Liu X, Tian J, Bai Q, Ashraf MA, Sarfraz M, Zhao B. The effect and action mechanism of resveratrol on the vascular endothelial cell by high glucose treatment. Saudi J Biol Sci. 2016;23:S16-21. doi:10.1016/j.sjbs.2015.06.021.

47. Grosso A, Cheung N, Veglio F, Wong TY. Similarities and differences in early retinal phenotypes in hypertension and diabetes. J Hypertens. 2011;29:1667-75. doi:10.1097/HJH.0b013e3283496655.

48. Duncan BB, Wong TY, Tyroler HA, Davis CE, Fuchs FD. Hypertensive retinopathy and incident coronary heart disease in high risk men. Br J Ophthalmol. 2002:86:1002-6.

\section{Submit your next manuscript to BioMed Central and we will help you at every step:}

- We accept pre-submission inquiries

- Our selector tool helps you to find the most relevant journal

- We provide round the clock customer support

- Convenient online submission

- Thorough peer review

- Inclusion in PubMed and all major indexing services

- Maximum visibility for your research

Submit your manuscript at www.biomedcentral.com/submit
C Biomed Central 